Orbis Tertius, vol. XXIV, no 29, e109, mayo-octubre 2019. ISSN 1851-7811

Universidad Nacional de La Plata

Facultad de Humanidades y Ciencias de la Educación

Centro de Estudios de Teoría y Crítica Literaria

\title{
Experiencia y fotografía: Shiki Nagaoka de Mario Bellatin
}

\section{Experience and photography: Shiki Nagaoka, by Mario Bellatin}

\section{Leonel Cherri}

Universidad Nacional de Tres de Febrero,

Argentina clcherri@hotmail.com

\section{Resumen:}

El presente trabajo aborda la problemática de la figura "autor" en Shiki Nagaoka: una nariz de ficción (2001) de Mario Bellatin. Texto singular que, hipotetizamos, representa un punto de inflexión en la obra del autor. En este sentido, se sostiene que la aparición de la fotografia en un texto que tiene por foco reflexivo el lenguaje de la literatura y la imagen de autor supone un encuentro no sólo deseado sino, fundamentalmente, sintomático. El trabajo explora y precisa los sentidos de dicha encrucijada tomando como marco teórico general las problemáticas planteadas por Walter Benjamin en relación con el aura y la destrucción de la experiencia.

Palabras Clave: Imagen/literatura, Autor, Fotografia, Literatura latinoamericana, Mario Bellatin.

\section{Abstract:}

This article addresses the issues with the role of the 'author' in Shiki Nagaoka: una nariz de ficción (2001) by Mario Bellatin. A singular text which, we hypothesize, represents a turning point among the author's works. In this sense, we argue that the appearance of photography in a text that focuses its reflection on the language of literature and the authorial image implies an encounter both desired and, fundamentally, symptomatic. The article explores the senses of this encounter, with the general theoretical framework of those issues raised by Walter Benjamin in connection with the aura and the destruction of experience.

KeYwORDs: Image/literatura, Author, Photography, Latin American literature, Mario Bellatin.

\section{INTRODUCCIÓN}

La fotografía en la obra de Mario Bellatin aparece por momentos que son particularmente densos. Momentos pues Bellatin saca fotos cotidianamente y, sin embargo, no siempre las incluye en sus libros. Decimos densidad pues se trata de una operación que de un momento a otro aparece en cuatro libros, entre 2001 y 2004 y, luego de un intervalo, en otros cuatro libros entre 2007 y 2009, mientras que en estos últimos años la fotografía ha aparecido más en el plano sus reflexiones metateóricas. Es ejemplar El libro uruguayode los muertos (2012) en general y el decálogo de la cámara Diana que allí se encuentra, en particular. Así las cosas, deberíamos señalar dos cuestiones. En primer lugar, que cada aparición dela fotografía en la obra de Bellatin supone marcos de interrogación que la exceden y que no pueden terminar de comprenderse sino analizamos el campo de operaciones en el que se inserta. Y, por otro lado, que el punto más radical de su intervención es una exploración de la inseparabilidad entre lo verbal y lo visual, entre lo real y lo imaginario, entre lo vivo y lo escrito.

En Condición de las flores Bellatin dice "contemplar los textos como si fueran imágenes" (2008, p. 10), en Disecado llama "sucesos de escritura" a todas esas "acciones plásticas" que "consisten en escribir sin utilizar los métodos clásicos de escritor como por ejemplo las palabras” (2011, p. 19) y en El libro uruguayo de los muertos dice dedicarse "sólo a escribir y a tomar fotos" pues entre la foto y el texto no hay más que una "amalgama" que "significa que no puede existir una sin la otra. La imagen sin el texto y viceversa" (2012, p. 124). Este arco de formulaciones resume, naturalmente, lo que hoy conocemos como "escribir sin escribir" y que fue formulado por primera vez luego de publicar Efecto invernadero,pero con los términos de crear una "especie de pre-historia literaria” (1992, p. 12). Se trata de una lógica que, si bien adquiere modulaciones nítidamente marcadas en la obra de Bellatin, sin embargo, mantiene una serie de constantes. Como, por ejemplo, una interrogación por la literatura y por la imagen del autor/escritor/artista. 
Por consiguiente, y luego de analizar en otros trabajos estos dos momentos, ${ }^{1}$ ha surgido la pregunta por cómo y dónde se produce en la obra de Bellatin el punto de inflexión de estas consideraciones y, si es que lo hubiera, sino es acaso el primer libro de su obra en que aparecen fotografías un momento singular de este sistema o proceso. Me gustaría entonces interrogar las condiciones de esa aparición no tanto para producir una generalización del concepto de escritura o de fotografía que allí aparece sino para captar sus primeras modulaciones.

\section{Fotografía E IMAgINACIÓN}

En la obra édita de Mario Bellatin, la aparición de fotografías en sus libros data del año 2001. El libro en cuestión es Shiki Nagaoka: una nariz de ficción, una suerte de biografía o comentario que relata la vida y obra de Shiki Nagaoka, un ignoto escritor (¿japonés?) cuya "nariz descomunal, hizo que fuera considerado por muchos un personaje de ficción” (2005, p. 231). ${ }^{2}$ Resumo el texto brevemente.

Los comienzos de Shiki, influenciados por "preceptos clásicos", orientaban su escritura a "describir las dimensiones del apéndice" y a explorar las distorsiones del "olfato" como de "la capacidad de respirar" (216). El aprendizaje de una variedad de "lenguas extranjeras" lo lleva a afirmar que en la traducción se encuentra "la real esencia de lo literario": "sólo trasladando los relatos de una caligrafía occidental a ideogramas tradicionales, es posible conocer las verdaderas posibilidades artísticas de cualquier obra” (216). Luego de ser humillado por su sirviente y amante deforme, Shiki se recluye en un monasterio en busca de una experiencia metafísica del lenguaje: allí, arrebatado por un trance místico, prende fuego tanto sus manuscritos como los bosques del monasterio, comprobando el carácter profético del lenguaje: el fuego se había originado a causa de "la pasión que había puesto en sus oraciones" (220). Antes, durante y después de estos sucesos, el texto va narrando la fascinación de Shiki por el registro fotográfico, ese "privilegio" de "contar con imágenes visuales" que "reproducían al instante lo que las palabras y los ideogramas tardaban tanto en representar" (217). Acaba poniendo un negocio de revelado, e influenciado por las ideas de Junichiro -su cliente principalque definen la fotografía como "un elemento de manipulación de la realidad" (224), Shiki publica Fotos y palabras, libro que tendrá en América Latina una importancia insoslayable, especialmente en el trabajo de "Rulfo y Arguedas": escritores "fragmentarios" y "mínimos" que, deslumbrados por la imagen, mueren buscando realizar una obra totalizante (225-226). Donde ellos fracasaron, parece sugerir el relato, triunfó Shiki: en "sus años finales" escribió un libro "fundamental" que "no existe en ninguna lengua conocida" (228). Según Etsuko, la hermana, para Shiki se trataba de "un bello ensayo sobre las relaciones entre la escritura y los defectos físicos, y sobre cómo la literatura que de allí surge debe distanciarse de la realidad apelando al lenguaje, en este caso al no-lenguaje" (233).

El desarrollo del relato, bien mirado, parece una suerte de excusa que para narrar otro relato: el de la literatura y sus instituciones. La mención de elementos, procedimientos e ideas artísticas compone no tanto un programa o ars poética sino, más bien, un campo de fuerzas donde las tensiones polares se desustancian transformándose en una analogía bipolar (Agamben, 2010, pp. 25-26). El relato va y viene de la superabundancia al minimalismo, del tema a la letra, del carnaval referencial de la nariz a lo neutro de la no-referencia, de Oriente a América Latina, de la literatura al misticismo, de la escritura a la traducción, de la imagen al no-lenguaje.

Esta situación del relato es un aspecto presente en todos los textos de Bellatin: girar en torno a una multiplicidad de relatos que le son previos (Ruiz, 2008, p. 203). En el caso de Shiki Nagaoka, su epígrafe envía al lector a un texto anónimo del siglo XIII titulado La nariz y a un cuento de Akutagawa de idéntico título -la primera edición de Sudamericana y la segunda de la PUC de Perú incluían los textos completos bajo el título "Dos narraciones clásicas sobre el tema de la nariz". Funcionan en la misma sintonía el relato de la hermana de Shiki (protectora y editora de los manuscritos) y el rumor, apreciable en fórmulas como "se dice que", "se sabe que", "se comenta que", "no se ha esclarecido si". De modo más abstracto, una serie de 
nombres (de autores, de películas, de textos literarios y críticos e, incluso, de conceptos) contagian la ficción con los relatos de la crítica o del comentario literario y, a la inversa, las instituciones literarias y sus prácticas exponen la ficción que tienen por fuerza. De ese modo, la vida y obra, la literatura y la biografía de Shiki ese relato- entran en una suerte de indiferencia.

Sobre el final del libro se consignan los textos de Shiki Nagaoka sin fecha ni editorial. Del mismo modo, bajo el título de "Algunas obras sobre el autor", se consigna la bibliografía crítica sobre Shiki Nagaoka.

Por último, el libro nos entrega los "Documentos fotográficos sobre Shiki Nagaoka” presentados como una "Recuperación iconográfica" a cargo de Ximena Berecochea: sus padres, sus escritos, mapas, dibujos, los utensilios para limpiar su nariz grasienta.

Se tratan de fotos en blanco y negro en las que se instaura puras resistencias visuales: opacidades, barridos, traslucidez, superposiciones, etc. Es ejemplar, al respecto, "Graduados de la quinta promoción de la escuela de lenguas extranjeras Lord Byron, donde Shiki Nagaoka fue uno de los más destacados alumnos. Nótese el círculo" (Figura 1).

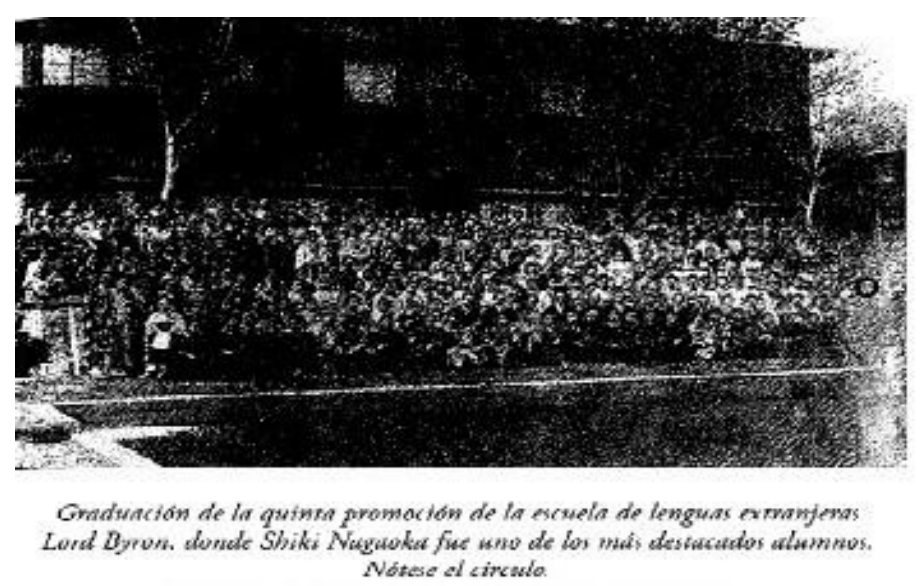

El efecto no puede ser más irónico: como vemos, dentro de ese círculo que alguien trazó estaría nada menos que un rostro. En la fotografía esa singularidad se presenta desgastada (¿por el tiempo?), y el montaje al señalar no demarca un punto de reconocimiento sino, por el contrario, un gesto indicial: lo que notamos no es ningún rostro sino, justamente, su señalamiento. El lenguaje renueva las relaciones de extrañamiento, pues "esta” y no otra es la situación del alumno destacado: no él (sus características físicas o mentales), ni tampoco su rostro (aquello que exterioriza singularmente su interioridad en una superficie) sino el círculo que lo demarca en una foto.

Es esto lo que en Shiki Nagaoka se estaría aclarando al pie de la imagen: el señalamiento, no de qué es lo que vemos - puesto que el maltrato de las imágenes nos muestra puras opacidades - sino de lo que ha sido y que, sin embargo, no sabemos ni que fue ni es. Lo intratable de la fotografía es ese interfuit: "lo que veo se ha encontrado allí" pero "ha sido inmediatamente separado", ha estado "absolutamente presente" y, $\sin$ embargo, "diferido ya", y ese lugar "se extiende entre el infinito y el sujeto" (Barthes, 2007, pp. 136-137). ¿Ese interfuit entre el infinito y el sujeto no es, acaso, lo que Walter Benjamin definía por aura en su "Pequeña historia de la fotografía"? Eso "que va más allá de un elemental dar testimonio del arte fotográfico", ese "algo que no es posible hacer callar", y que "nos obliga a preguntar cómo se llamaba esa persona que vivió por entonces, y que hoy sigue siendo tan real que no va a disolverse por completo jamás en el 'arte” (Benjamin, 2007, pp. 381-382), esa "chispa de individualidad, de ese aquí y ahora con que la realidad ha abrasado la imagen” (382) haciendo de ella "la irrepetible aparición de una lejanía” por "más cerca que se halle" (394).

En las fotos de Shiki Nagaoka el aura no es, paradójicamente, aquello que consume la imagen sino, por el contrario, lo que permite desplegar un espacio cualquiera, que tampoco se sintetiza como un "universal abstracto, en todo tiempo, en todo lugar" sino que se presenta como una singularidad "que ha perdido su homogeneidad", sus "relaciones métricas": ese rostro opaco que hace notar al círculo que lo distingue. Lo cualquiera instaura una "conjunción virtual”, un "puro lugar de lo posible”. Es, entonces, la aplicación de una 
inestabilidad a la imagen lo que despliega una "riqueza de potenciales [...] que son las condiciones previas a toda actualización" (Deleuze, 1984, pp.160-161).

Esa inestabilidad es la construcción de una suerte de extrañamiento producida en la intersección de la opacidad del "montaje" fotográfico y la claridad irrisoria de la leyenda. El encuentro formal entre polaridades - donde la ficción se llena de una visualidad ridícula y la chispa de realidad es retornada hacia un delirio imaginario- recuerda aquella forma híbrida o bipolar de la Kriegsfibel (1955)de Bertolt Brecht que definiría en su diario como foto-epigrama. Los epigramas eran

\begin{abstract}
inscripciones grabadas por los griegos antiguos en el mármol de los sepulcros. Es por lo tanto un estilo funerario por excelencia donde, por otra parte, el muerto busca a menudo ofrecerse ante los ojos de aquel que se detiene ante su tumba [...] Luego, porque el epigrama sólo cobra su sentido en su valor ético: acabará designando toda poesía breve que oficie de 'sentencia' moral [...] Finalmente, por una inversión del sentido de las que tienen el secreto las supervivencias, el género del epigrama ha sabido relacionarse con la risa y la forma satírica, emparentándose desde entonces con algo así como un Witz moral, incluso político" (Didi-Huberman, 2008, pp. 52-53).
\end{abstract}

La forma "epigramática" que trabaja Bellatin -propia de su escritura, sea él u otro artista el que tome o recolecte las fotos- no carga con el peso histórico-político sino con el poético-experimental de la intervención brechtiana. Son formas breves, paródicas, hilarantes, satíricas incluso. Parecen poemas concretos o minimalistas que contienen nada más que "la simple indicación de una cosa, persona, acción" o que deducen "una conclusión a partir de premisas" (Didi-Huberman, 2008, p. 53).

Las foto-epigrama producen una suerte de saturación del juego entre ficción y biografía, entre escritura y vida. Los epigramas se encuentran a la sazón de parodiar burlonamente el uso biográfico de la fotografía, aquella expectativa documental que la fotografía no puede saldar sino recurriendo al lenguaje: "esto (visual) es esto (verbal)". Mientras que las fotografías, exigidas por los epigramas a mostrar puras singularidades invisibles, exponen un vaciamiento de visualidad constitutivo: la fragilidad que tiene por esencia.

Como señaló Benjamin, los "clichés" del reportaje donde las fotografías "no tienen otro efecto que el de asociarse en el espectador a indicaciones lingüísticas" son tan fetichistas como el fijado de "imágenes ocultas o fugaces cuyo shock en el observador detiene el mecanismo de asociación" (2007, p. 403). Por eso, para salvar a la fotografía del "embelesamiento" y de la "fascinación" y convertirla en un medio de "conocimiento" y de "experimentación” es preciso que intervenga "el pie de foto, es decir, la leyenda que integra a la fotografía en la literarización general de toda vida y sin la cual la construcción fotográfica misma nos resulta imprecisa [...] ¿Un fotógrafo que no lee sus propias imágenes, no es menos analfabeto que aquel que ignora la fotografía? ¿No es la leyenda, entonces, uno de los componentes esenciales de las fotos?” (Benjamin, 2007, pp. 403-404). En síntesis, lo que Bellatin constata - que el precio de mostrar(se) se pague con la imposibilidad de decir(se) y viceversa- no implica una detención de la relación entre escritura y fotografía por dilemática sino la activación radical de su bipolaridad.

Podríamos decir junto con Alan Pauls (2005) que la obra de Bellatin hace productiva una "histeria fría" entre fotografía y escritura, entre instante y permanencia, siempre y cuando acotemos -como precisa Walker (2009, p. 3) - que esa relación entre lo visible y lo legible no es esencial o sintética sino, más bien, analógica. Pues los efectos de la tensión entre lo visible y lo legible no corresponden dicotómicamente a las imágenes, por un lado, y a los nombres, por el otro, sino a la analogía bipolar que los distingue y desdiferencia.

En ese sentido, la irrupción del lenguaje al pie de la fotografía es lo que extrapola la inestabilidad de las imágenes, instaurando una suerte de roce absurdo que hace delirar el registro fotográfico llevándolo a su plano de inmanencia: ${ }^{3}$ lo in-fotografiable, aquello que solo puede ser fotografiado cuando el sentido común ya no está allí para limitar lo sensible y los órganos de la percepción se han vuelto metafísicos o, en términos benjamineanos, cuando el inconsciente óptico no constituye una revelación de lo visible sino la posibilidad de una experiencia.

Se concluye, entonces, que la operación paródica/satírica es fundamentalmente creativa: si la “documentación iconográfica" opera sobre lo ridículo de la mostración biográfica en tanto que prueba de la 
existencia de lo existente, es sobre esa pretensión de algún tipo de verdad que Bellatin estaría construyendo una prueba de la existencia de lo inexistente. Por consiguiente, la fotografía se vuelve un campo agujereado que solo puede atravesarse vía la imaginación por medio de la escritura. Y lo que en ella vive es re-adquirido.

La primera "iconografía", por ejemplo, muestra a los "padres de Shiki Nagaoka" e indica "Nótese la modernidad de costumbres, evidenciada en los guantes y lentes de Zenchi Fukuda y en el uso de lápiz labial de Zenchi Zachiko, lo que de algún modo demuestra su pertenencia a la clase aristocrática" (Figura 2).

En otras palabras, la Historia de una fotografía (de los tejidos, de las modas, de las culturas, de los adornos, es decir, lo que en Shiki Nagaoka podría responder al nombre de "lo oriental" o "lo exótico") se vuelve permeable, en mayor o menor medida, por este efecto de verdad que pretende crear un nuevo orden (imaginario) donde la realidad de su ha sido es actualizada sin perder por eso un resto aurático que persiste frente a nosotros: aquella imagen, por más agujereada que se nos presente, no deja de ser una fotografía y, fundamentalmente, la fotografía de unos rostros. Y el rosto, se nos dijo, es el último refugio del aura que puso a la imagen fotográfica en una situación de inconmensurabilidad: la de presentarse como algo que vive todavía, como algo que carga con una animosidad tal capaz de devolvernos la mirada. Es ejemplar, al respecto, la "Fotografia de Shiki Nagaoka manipulada por su hermana Etsuko, con el fin de evitar que el autor fuera considerado un personaje de ficción" (Figura 3).



Zenchi Fukuda y Zenchi Sachiko, padres de Shiki Nagaoka Notese la modernidad de costumbres, evidenciada en lor guantes y lentes de Zenchi Fukuda y en el uso de lapiz labual de Zencht Sachiko, lo que de algin modo demuestra ss pertenencia a la clase arisocrdrica

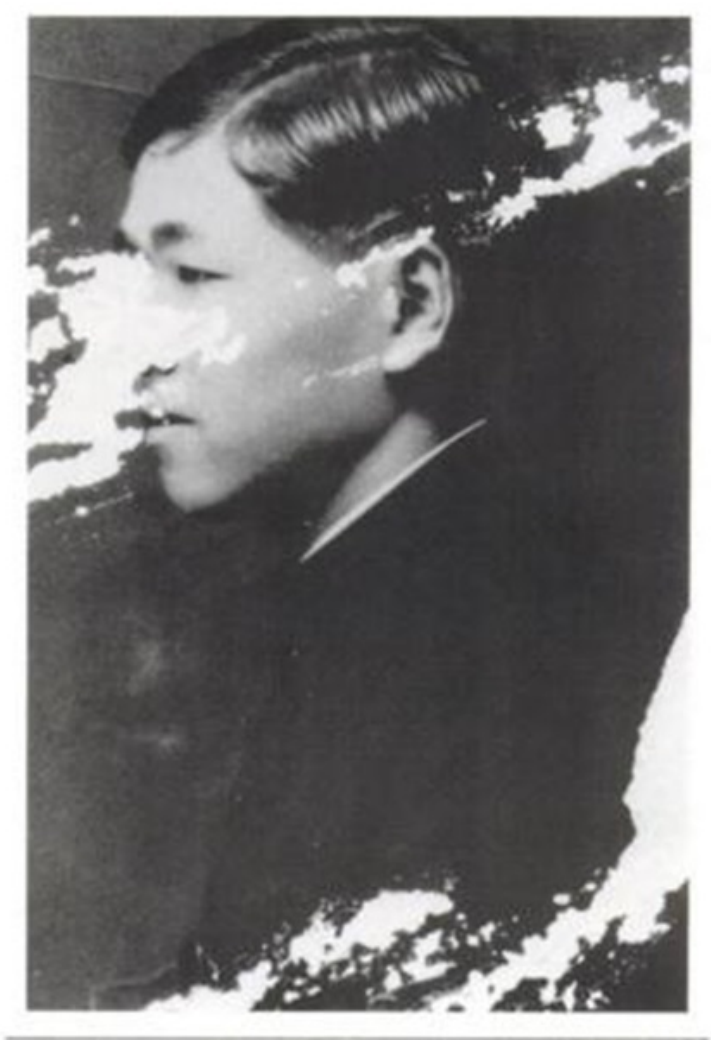

Fotografia de Nagaoka Sbiki manipulada por su bermana, Etsuko, con d fin de evitar que el autor fuera considerado personaje de ficción.

\section{Regímenes DE VISUALIDAD: LA NARIZ Y EL NO-LENGUAJE}

Volvamos al comienzo: "Lo extraño del físico de Nagaoka Shiki, evidenciado en la presencia de una nariz descomunal, hizo que fuera considerado por muchos como un personaje de ficción" (Bellatin, 2005, p. 215). Promediando la mitad del relato se nos dice que el verdadero nombre de Shiki es "Naigu Zenchi" (218), el mismo nombre del personaje de Akutagawa. Y al final, se nos presenta la fotografía del rostro de "un ser de ficción”. Sin embargo, allí donde algún tipo de verdaddebería ofrecerse a la vista, se produce una operación 
táctil (una rasgadura) cuyo efecto (el confinamiento visual de la nariz) evitaría que el autor acabe siendo un personaje de ficción. La paradoja es evidente: si el montaje (la rasgadura) salvaría a Shiki (ese apéndice enorme y grasiento) de las garras de la ficción, en la medida en que se ejecuta la operación se define no sólo el régimen o condición de posibilidad de la ficción sino, también, de lo real. En otras palabras, ya "no se trata entonces de que la verdad tenga estructura de ficción" sino "de algo mucho más grave (quiero decir: de mayor alcance y de mayor contradicción): a lo real hay que imaginárselo" (Link, 2009, p. 119).

Examinemos el inicio de la narración de Akutagawa: "No hay nadie, en todo Ike-no-wo, que no conozca la nariz de Zenchi Naigu. Medirá unos 16 centímetros, y es como un colgajo que desciende hasta más abajo del mentón. Es de grosor parejo desde el comienzo al fin; en una palabra, una cosa larga, con aspecto de embutido, que le cae desde el centro de la cara" (Bellatin, 2002, p. 85). En ese sentido, el rasgado no es solo una propiedad del reconstrucción iconográfica de "Ximena Berecochea", pues si Shiki Nagaoka es una operación sobre el texto de Akutagawa, esta se realiza al agujerear campos, vaciar puntos, cortar el lenguaje, es decir, propiciar una inestabilidad en las relaciones métricas con el fin de generar esa fuerza de misterio que impulsa al relato.

Ver los cuerpos "n'est pas dévoiler un mystère, c'est voir ce qui s'offre à voir": una imagen que "est étrangère à tout imaginaire, à toute apparence -et de même, à toute interprétation, à toute déchiffrement" (Nancy, 2000, p. 46). Pero, en nuestro caso, la nariz no se ofrece a la vista e, incluso, no es tanto "la nariz" aquello que se resiste sino su tamaño. Lo que en el conjunto de elementos orientales se vuelve exótico/extraño para lo exótico/extraño.

¿Pero si ya hay una operación formal y temática de extrañamiento de lo extraño, cuál es el sentido de confinar al vacío esta parte tan particular de lo visible? La nariz se presenta como una ostentación y una complicidad con lo visible que aunque no supone un enigma por resolver, produce un misterio - una ocultación insoslayable - que la envuelve en su extensión: al instaurar un exceso nominal y métrico en torno al apéndice, las operaciones de montaje potencian sus sentidos. Vía la nariz, el cuerpo de la ficción y la imagen de autor se envuelven en un misterio vitalista de mutuo engendramiento y deceso cuya diferencia se aprecia en la variación mínima del montaje. Si, como dijimos, la fotografía del rostro nos trae a colación la cuestión del aura; cuando esa singularidad es, además, la "imagen de un autor", surge la problemática del fetichismo artístico. En estos términos, el confinamiento visual de la nariz adquiere unos sentidos específicos.

$\mathrm{Al}$ respecto, conviene recuperar la célebre lectura de Freud en su artículo sobre "Fetichismo" de 1927. Es el "brillo sobre la nariz", Glanz auf der Nase en Alemán, lo que atrae a un determinado paciente cada vez que lo descubre en ciertas mujeres. La lengua materna y olvidada del paciente era el inglés: el brillo, es decir el Glance, es también una mirada. Freud, lo admite, apresura la interpretación: para cada sujeto el fetiche es algo específico pero, a la vez, es siempre lo mismo: un sustituto del pene, no uno cualquiera sino uno particular, el falo materno (1927, p. 161-162). Es decir, si Freud se apresura es porque el falo materno, en el diagrama de la castración, le viene como anillo al dedo. Sin embargo, ese doble régimen del fetiche señala algo más: que cualquier objeto pueda ser virtualmente un fetiche, termina por minar la presuposición de una ur-forma u objeto-tipo. Si "el pene no tiene forma de pene 'entonces tal vez una época obsesionada con la necesidad de castración ha alcanzado su ocaso"' (Echevarren, 1998, p. 25). ¿Tal razón explica que Freud no insista en la otra asociación significante, igualmente latente, la del alemán Glanzcon el inglés Glans, es decir, el glande? Ese devaneo leve (glanz, glance, glans), lejos de tipificar el objeto fetichista, estaría señalando un diagrama diferente, uno que lo presenta como vacío constitutivo: el fetiche es un objeto, si se quiere, pero confinado a ese infinito que el psicoanálisis llama desplazamiento y el arte pop llama serie.

Lacan postuló en 1958 al "falo como significante de la razón del deseo (en la acepción en que el término es empleado como 'media y extrema razón' de la división armónica)" ("La significación del Falo"). Posteriormente, el 19 de abril de 1967 en el Seminario XIV sobre La lógica del fantasma, Lacan explica que el número de oro ("nombre d'or")es aquel que "pour parvenir à une certaine limite d'approximation, demande de tout les formes —elles sont multiples et presque infinit - de l'incommensurable, [...] demande le plus d'opérations" (1967, p. 9). Por eso, "il n'y aura jamais d'arrêt ni de terme à ces opérations" (10). Es decir, el 
objeto-a y la razón áurea entran en una relación de semejanza que otorga soporte y función simbólica como densidad al deseo que, se nos dice, no tiene término. No podemos obviar la seriedad de tales signaturas: lo inconmensurable y la serie infinita. Lo que equivale, en nuestro caso, al montaje del rasgado y a la (re)escritura como corte.

Por otro lado, lo que también conviene tomarse en serio aunque se trate de un chiste realizado a cierta Sociedad de Artistas Independientes (New York) es el salto epistémico sobre el centro del cuerpo que produjo el mingitorio puesto en perspectiva de Marcel Duchamp firmado por R. Mutt que hace todo lo contrario de la semejanza clásica, pues impugna "toda noción de centro, al situar metonímicamente el problema de la divina proporción (de la verga) fuera de cuadro: un centro ausente en su lugar” (Link, 2015, p. 175). The Fountain (1917) "cita solo por metonimia o vacío aquello que durante siglos constituyó, al mismo tiempo, el centro de la soberanía y el centro (naturalmente, heteronormativo) de los cuerpos. Lo que funda ese ready-made es un cuerpo nuevo que "falta en su lugar [...] un cuerpo áfalo, acéfalo, inorgánico" (Link, 2015, p. 179). Lo "mismo" podríamos leer en un rostro opaco señalado por un círculo (acéfalo), en una foto de perfil rasgada (áfalo) y, por consiguiente, en la des-obra signada por la reescritura y el montaje (inorgánico).

En este punto la polémica del mingitorio nos exige retomar la cuestión del fetichismo pues la Sociedad de Artistas Independientes rechazó, no la obra de Duchamp, sino la obra de "R. Mutt". Ese rechazo, en cierto punto, constata el paradigma fetichista del nombre de autor que al presentarse al igual que el apéndice en su ausencia (pues R. Mutt no designaba persona alguna sino un puro vacío) devaluó hasta el grado cero la exposición de la obra. No fue un desacierto de André Breton sino una receptividad epocal lo que llevó a definir al ready-made vía la soberanía de la elección del artista que mediante su firma y una operación nominalista dotaba al objeto de estatuto artístico. Tampoco se equivocaba el dadaísmo que al realzar el valor de culto del artista, generalmente de modo abyecto, lo volvía una suerte de rey Midas que convertía a los objetos no en oro sino en "obra de arte" (De Duve, 2007, pp. 215-216).

Esta cuestión se presenta en varias iconografías de Shiki. De ese modo, vemos-leemos el "Cuenco que contenía el agua hervida necesaria para el tratamiento de la nariz", el "Exprimidor de nariz", el "Vaso preparado para recibir la grasa eliminada por medio del tratamiento", el "Espejo que usó Shiki Nagaoka para apreciar los resultados experimentados en su nariz", la "Vajilla que utilizó Shiki Nagaoka en la casa donde pasó sus últimos años", el "Calzado que el autor se colocó a diario para ir a trabajar al kiosco fotográfico", etc. Sea lo escatológico (la nariz grasienta) o lo anodino (el calzado diario) lo que se señala es el carácter fetichista de esa puesta en escena de la inexistencia. Este punto, la fetichización de lo inexistente o ausente, es lo que permite reapreciar críticamente la operación.

En 1961 Piero Manzoni presentó las noventa latas de Merda d'artista haciendo equivaler el gramo de mierda al de oro. Allí, más allá de la relación entre mierda y oro, como también entre analidad y arte, se produce una deriva del cuerpo del artista hasta sus desechos que se encuentran "enlatados". Ese circuito productivo pone al arte y a la autofiguración del artista en una situación de confinamiento: un vacío visual en el que la posibilidad de ver se encuentra, cuál tragedia placentaria y sinestésica, al alcance de la mano. Esa tragedia ya se había presentado antes en Fiato d'artista donde lo que es dado, en este caso el aliento, se encuentra contenido por globos. De ese modo, lo somático, sea del orden del desecho (el artista como máquina excrementaría) o del orden de la posibilidad productiva (el artista como máquina deseante) es sometido a un orden pre-verbal (la lata, el globo, el huevo, la placenta) y, por eso mismo, a un régimen de visualidad confinada (un vacío visual que apela a otro tipo de contacto sensible).

En síntesis: podríamos pensar la fetichización del autor en la iconografía de Shiki Nagaoka (esa sobreexhibición) como una producción de efectos paradójicos pues, al igual que los objetos de Manzoni, genera "frustración deliberada de nuestra sensación visual" lo que podría leerse como una "estrategia de resistencia contra la conversión de la cultura [y el arte] en espectáculo” (Foster et al, 2006, p. 414). El movimiento es doble: se articula nominalmente una sobre-exposición de algo que no deja verse pero que resiste, presente, bajo la forma del vacío pre-nominal que lo des-crea. Esa frustración, somática y pre-verbal, cuyo régimen es 
abyecto-deseante se expresa ejemplarmente en otra iconografía (Figura 4) cuyo epígrafe reza: "Símbolo con el que se conoce el libro intraducible de Shiki Nagaoka" (Bellatin, 2005, p. 44).

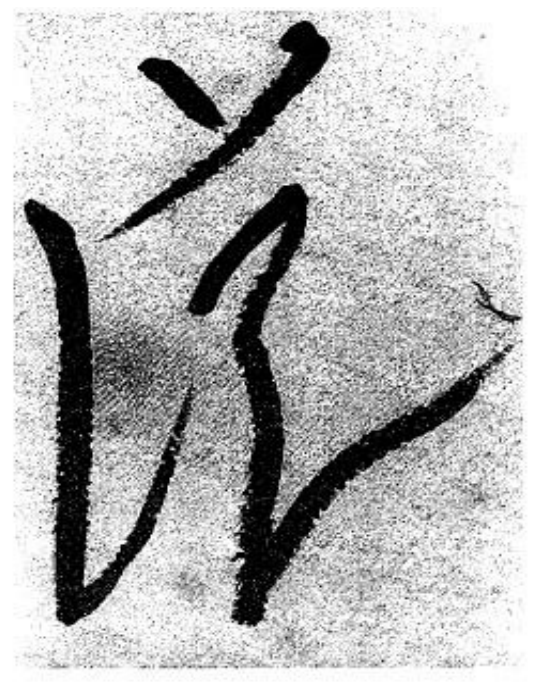

Simbolo con el que se conoce el libro intraducible de Shiki Nagaoka.

El libro impronunciable e intraducible -que no por eso deja de ser leído, editado e interpretado, pues cuenta incluso jcon bibliografía crítica!- se presenta como la pura materialidad sin contenido. Es imagen (pues expone la visualidad de un puro cuerpo que piensa) pero es letra (pues se trata de un significante que, aunque no estaría desprovisto de significado, se expresa directamente en su no-pensamiento). Sin embargo, ni el relato ni la fotografía resuelven una incertidumbre crucial, al contrario, la acentúan: ¿el símbolo es meramente un título -operativo, pues el libro carece de todo nombre- o es, nada más y nada menos, que el libro mismo? De cualquier modo, esa letra sin-lenguaje o lenguaje pre-verbal envía, en efecto, a las inscripciones pre-históricas en general.

Podríamos recordar, por ejemplo, el Kohau rongorongo: esas misteriosas inscripciones en tablas de madera halladas en la Isla de Pascua. El caso es célebre para la etnografía pues, para las corrientes funcionalistas, se trataba del "descubrimiento" de una escritura. Sin embargo, como señaló Raúl Antelo, fue Alfred Métraux en su libro dedicado al tema quien concluyó que no se trataba

\begin{abstract}
de una auténtica escritura y por lo tanto del umbral de la historia para esa cultura, sino de simples fórmulas mnemotécnicas que recién más tarde adquirirían valor sagrado para sus usuarios. Métraux llegaba a ese convencimiento porque, a la manera mimológica de Mallarme, leia tales inscripciones a partir de una muy precisa concepción del lenguaje, la de un puro espacio de la ficción, y no veía en él un instrumento de comunicación o fundación de comunidad. No hay razón en el lenguaje, hay tan solo juegos de poder. [Desde esa óptica, es el olvido el] auténtico ritual de fundación de una literatura, como si ésta buscase, a través de la amnesia, reanudar los vínculos con el improbable origen, y como si la palabra misma no dispusiese de ninguna archè para afianzar sus fundamentes (Métraux, 2015, p. 380).
\end{abstract}

La escritura, entonces, no sería un remedio contra el olvido sino contra la memoria. Pero también, ciertamente, un don: la falta de fundamento de una literatura. Así las cosas, el crítico concluye equiparando esta concepción mnemónica -que va desde un pueblo que falta, pasando por los poetas modernos y llegando a un antropólogo de avanzada- a las posautonómicas: "aquello que define la literatura al carecer de un marco fundacional inequívoco es, por el contrario, la infinita oscilación en su inefabilidad. Tales inscripciones son, como diría Ludmer, ralidadficción, y otra no es la consistencia paradojal de la máquina mitológica" (2015, p. 380-381).

Esa situación de infinita inefabilidad y de realidadficción no sólo está dada en Shiki Nagaoka, como venimos viendo, sino también en su pre-texto creativo.

A mediados del año 2000, Bellatin fue invitado al palacio Bellas Artes a participar de un ciclo de charlas donde cada participante hablaba de su escritor favorito. Como declara en una entrevista del 2008, al cabo de 
un plazo de pensar su intervención advirtió lo obvio: "Que no puede haber un autor preferido, sobre todo porque escoger a uno elimina al resto. Fue por eso que decidí crear mi autor favorito, que creo apareció, sin darme mucha cuenta, como una suerte de alter ego" (Bellatin, 2016). La intervención por más seria que parezca tampoco fue reticente al chiste puesto que en ningún momento de la jornada la operación fue aclarada y, tiempo después, el escritor llegó a recibir una carta del Departamento de Literaturas Orientales de la Freiuniversität de Berlín pidiéndole información acerca del autor desconocido.

Un autor favorito, entonces, no implicaría una selección sobre un conjunto sino la construcción de una imagen que, paradójicamente, acaba siendo un alter ego. ¿Bellatin se avergüenza por el hecho de que su autor favorito sea su (im)propia imagen y por eso hay ficción? ¿O nos estaría diciendo que lo favorito no podría ser un autor sino el genius de cualquier autor: lo impropio, lo no-consciente sin denegación, vivir en la intimidad de un ser extraño, ese otro del que se forma parte pero como nuestra vida en tanto que no nos pertenece?

De aquí la pertinencia y el éxito de operaciones irónicas como las de las vanguardias, en las cuales la presencia de Genius era atestiguada mediante la de-creación, la destrucción de la obra. Pero si sólo una obra revocada y deshecha puede ser digna de Genius, si el artista verdaderamente genial es el artista sin obra, el Yo-Duchamp no podrá nunca coincidir con Genius y, en la admiración general, se va de viaje por el mundo como la melancólica prueba de la propia inexistencia, como el tristemente célebre portador de su propia inoperancia (Agamben, 2005, pp. 11-12).

Por eso mismo, Shiki no es pura de-creación, como tampoco puro artificio o juego: lo que equivaldría a probar la propia inexistencia, a portar su propia inoperancia. En ese sentido, vía la paradoja o la bipolaridad entendidas como operaciones que no disuelven sino que mantienen tensiones, lo que leemos es una semejanza (a)simétrica que se distancia tanto de posiciones "clasicistas", como de las "vanguardistas", como también incluso de las "posautonómicas".

Esta preocupación por el estatuto literario, especialmente en lo que respecta a la imagen de autor/escritor, está presente en los comienzos mismo de la obra de Bellatin: Montiel, personaje principal de Las mujeres de sal (1986), es un pintor acabado que busca una singular experiencia estética (Cherri 2017b), en Efecto invernadero (1992) un poeta prepara la escena de su muerte como quien prepara una novela, en Poeta ciego (1998) la literatura y la secta político-comunal se confunden articuladas por la figura de su líder-poeta. Sin embargo, con El jardín de la señora Murakami (2000) el autor ya no es una figura que la novela vuelve tema sino que aparece como la ficción que origina el texto: pues Bellatin es no ya el autor sino el traductor de un libro inexistente. Esa es la lógica que atraviesa Shiki Nagaoka, pero que Bellatin la lleva a un punto más allá que en El jardín de la señora Murakami.

Podríamos concluir que Shiki Nagaoka funciona en la obra de Bellatin como el punto de sutura entre el lenguaje (de la literatura) y la imagen (de autor): por un lado, la situación aporética de tener que sostener una escritura cuya lengua le es completamente ajena o ausente -lo que ya había ensayado en El jardin, pero que en Shiki cobra un relieve material al incorporar fotografias, ese lenguaje extranjero- y, por otro lado, la situación paradojal de reunir en una obra (un libro, una fotografía) la escisión de un sí mismo múltiple que se extiende en su diferencia.

La inflexión que provoca Shiki Nagaoka en la obra de Bellatin es tal conjunción. Y, con ella, se produce una radicalización del campo de operaciones en que estas problemáticas se insertan. Jacobo el mutante (2002), libro con fotos pero sin epígrafes colocará el autor y la literatura en el lugar del comentario de una obra inexistente y hará de las fronteras y las mutaciones sus metáforas y figuras; Perros héroes (2003), libro con fotos y epígrafes, se presenta como el libro que el autor escribió cuando era niño y que encontró al fotografiar un lugar en la que se encontraba un estado de "ficción pura", el Congreso de Dobles de Escritores (2003)pone al autor en el lugar del doble y Underwood portátil. Modelo 1915 (2005) resume, por medio de la máquina de escribir y su modelo, una suerte de ars poética de todo esto. Los ejemplos no son azarosos, sino que pretenden proponer una hipótesis general y otra específica. Por un lado, y como ya hemos sostenido en otros trabajos, del 2000 al 2005 (la fecha de tales textos e intervenciones) se produciría en la obra de Bellatin una exploración e insistente reformulación de las preguntas por la imagen del autor y de la literatura (Cherri, 2015b; 2018). 
Y de modo más específico, y como hemos desarrollado en este trabajo, el lugar que ocupa Shiki Nagaoka en este marco es crucial. Pues los vínculos entre fotografías y epigramas que allí se trazan son la base de las interrogaciones venideras como del campo de operaciones en que las introduce y que, en términos teóricos, podríamos decir que replantean estéticamente la problemática del aura.

\section{EXERGO: AURA, AISTHESIS, EXPERIENCIA...}

En la década de 1930, Walter Benjamin presentaba el problema de la experiencia moderna como un choque de fuerzas del que participaban la anestesia y la sensibilidad. Enfrentamiento que era apreciable en la guerra, en la experiencia de la ciudad moderna, en las artes en general y en ciertas técnicas en particular: allí, un instante de peligro.

¿Cómo olvidar esa instantánea terrible que Benjamin formuló al final de su ensayo sobre la obra de arte?: la humanidad se transforma en objeto de contemplación de sí misma y entra en un proceso de autoalienación de semejante valía "que le permite vivenciar su propia aniquilación como un goce estético de primer orden” (1936, p. 136). Esto es, de un modo manifiesto, la realización absoluta del l'art pour l'art. En otras palabras: fiat ars pereat mundus.

En semejante sentencia como en la famosa frase respecto de los documentos de cultura y de barbarie (1940, Tesis 8), a la vez que queda expuesta la relación "fantasmática" que hay entre la vida de unos y la muerte de otros, se presenta otro problema formulado ejemplarmente: la interrogación por lo viviente no puede sino suponer una interrogación por las formas. Es decir, entre las formas y lo vivo hay una relación de inseparabilidad que Benjamin abordará de diversas maneras a lo largo de su obra. En ese sentido, hablar de cine implicó necesariamente reflexionar sobre la insensibilización de los cuerpos que la estetización de la violencia fascista producía; del mismo modo, la crisis de la narración y de la novela, como así también la aparición de la fotografía no pudo dejar de superponerse con una crisis de la experiencia, de la percepción y de la comunicabilidad. Si las formas de la técnica y del arte se relacionan tan intensamente con lo que vive es porque son producto de ese "circuito que va de la percepción sensorial a la respuesta motora" que "comienza y termina en el mundo" y en donde "el cerebro no es un cuerpo anatómico aislable, sino parte de un sistema que pasa a través de la persona y su ambiente" (Buck-Morss, 2005, p. 186). Si, en efecto, es esta la base del concepto de experiencia para Benjamin, su partenaire "estética" no será meramente la (des)estetización o (anti)representación moderna de lo "bello, verdadero y bueno" sino un conjunto de fuerzas (sensibles) que inclinan el arte hacia la vida como posibilidad de sentir/conocer/experimentar o hacia la muerte/anestesia como destrucción de la experiencia.

Es este el marco en el que surgen las distintas teorizaciones del "aura" que, vale aclarar, es un concepto que despliega dos dimensiones simultáneas y bipolares.

Por un lado, la noción de "tejido peculiar de espacio y tiempo" supone "la estructuración o las condiciones formales de nuestra intuición sensible del mundo" y, por consiguiente, el objeto de interés que perfila es "la estructura de la experiencia, es decir, la forma subyacente a la cual debe adaptarse toda experiencia para ser una experiencia, a diferencia del contenido de cualquier experiencia particular", de ahí que su carácter peculiar e irrepetible sea de "un orden totalmente distinto del de nuestra intuición cotidiana del mundo" (Costello, 2010, p. 114). Por eso, el ejemplo de la aparición aurática no puede ser más sintomático: "descansando en una tarde de verano...." (Benjamin, 2007, p. 394). En otras palabras, lo que pone de relieve el aura como categoría general de la experiencia o como categoría de la experiencia trascendente $e^{4}$ es la problemática del desvanecimiento de la experiencia en el mundo moderno: la destrucción de la experiencia que para que suceda no es de "ningún modo necesaria una catástrofe y que la pacífica existencia cotidiana en una gran ciudad es, a ese fin, perfectamente suficiente” (Agamben, 2007, p. 7). El ser humano (y el artista) se vuelven una mercancía entre otras. 
Por otro lado, al momento de analizar dicha crisis de la experiencia Benjamin hace aparecer el aura junto con formas y técnicas específicas (la novela, la fotografía, el cine, la poesía). En estas operaciones sería errado leer una ontologización sino, más bien, el trazado de una constelación en la que dichos elementos constituyen un marco formal y técnico que definen al aura como categoría histórica (Crimp, 1980, p. 94), especifica (Costello, 1989) y/o dialéctica (Oyarzún, 2008, p. 20). No es que la decadente fotografía de retrato sea aurática y el cine ruso no lo sea, sino que es la actitud del artista o la lógica del dispositivo "respecto de sus técnicas" (Benjamin, 2009, p. 385) lo que pone a funcionar al aura de una forma o de otra: reificando su valor cultual, reelaborándolo o, destruyéndolo. Lo que se deja leer en el "Ensayo sobre la obra de arte..." y que Howard Caygill denomina "nihilismo activo": la destrucción catártica de la herencia cultural a través de usos comunitarios de la tecnología como manera de abrir nuevas posibilidades para el arte. ${ }^{5}$ Pero el problema no es tan sencillo: la reproducción que separa los objetos de sus experiencias originales corre el peligro de volver homogéneo lo irrepetible; de igual modo, la destrucción de la tradición -entendida como base de comunicabilidad- no es algo meramente libertario sino que también amenaza socavar la posibilidad de toda experiencia, de ahí que la tarea del artista (como narrador/productor) sea operar sobre ese suelo común que la reproducción arruina, es decir, generando nuevas formas de devenir común. ${ }^{6}$ Lo que implica devolver la fuerza biológica-instintiva a los sentidos. Por tanto, no se trata ya de proponer formas de ver, oír y sentir, no ya una pedagogía de la mirada, la escucha, o del refinamiento de los sentidos para captar lo bello, lo bueno o lo verdadero, sino una experimentación radical del contacto con el mundo: "deshacer la alienación del sensorium corporal, restaurar la fuerza instintiva de los sentidos corporales humanos por el bien de la autopreservación de la humanidad (Buck-Morss, 2005, pp. 169-171). Es esta constelación estético-teórica lo que parece articularse con singularidad en la obra de Bellatin a partir de la publicación de Shiki Nagaoka. Me refiero a su trabajo con el aura tanto respecto del valor cultual (el fetichismo de autor pegado a la nariz) como respecto de la experiencia sensible (los fotoepigramas y lo infotografiable).

Lo "fotográfico" en Bellatin no es del orden del registro sino del "encuadre", entendiendo por esto las operaciones que interrogan la relación vida-mundo a través de "particulares concretos", explorando "la experiencia como algo radicalmente diferente de la vivencia", son textos que "contra toda apariencia [...] piensan lo viviente, se dejan llevar a un estrato de la relación vida-mundo donde la experiencia es o puede ser la del fracaso, del vacío, o de la nada. Una experiencia solo presunta, hipotética, conceptual, pero experiencia radical de la intemperie" (Link, 2009, p. 307). Por eso, los particulares concretos o puntos de existencia Shiki Nagaoka, ese autor de ficción- están a la sazón de fotografiar la literatura, es decir, de alcanzar un umbral de indiscernibilidad en donde los registros se confunden, entran en "coalescencia" y hacen que las formas “cobren vida, se independizen" (Deleuze, 1985, p. 98).

Por la vía regia de lo fotográfico -de modo abstracto en la escritura epigramática, de modo explícito en la inserción de fotografías- la vida se readquiere bajo nuevas formas, es ese y no otro su sentido último: encontrar el arte allí donde el aura parecía haber consumido toda imagen y hacer del aura el disparador de nuevas experiencias estéticas. Tales operaciones configuran una imagen de la literatura como exploración radical de la experiencia estética-afectiva, es decir, sensible.

\section{REFERENCIAS}

Agamben, G. (2005). Profanaciones. Buenos, Argentina: Adriana Hidalgo.

Agamben, G. (2007). Infancia e historia. Buenos, Argentina: Adriana Hidalgo.

Agamben, G. (2010). Signatura rerum. Sobre el método. Barcelona: Anagrama.

Antelo, R. (2008). Crítica acéfala. Buenos, Argentina: Grumo.

Antelo, R. (2015). El tiempo de una imagen, o el tiempo-con. Cuadernos de literatura 38, pp. 376-399.

Arévalo, J. (4 de diciembre de 1992). Efecto invernadero: un nuevo estilo de la novela en Mario Bellatin. El comercial. 
Arrieta, D. (2015). Intertextualidad, dialogismo y poética cognitica en la novela contemporánea: Bernardo Carvalho, Eduardo Lago y Mario Bellatin. Tesis Doctoral. Madrid: Universidad Complutense de Madrid.

Barthes, R. (1989). La cámara lúcida. Barcelona, España: Paidós.

Bellatin, M. (2002). Shiki Nagaoka: una nariz de ficción. Lima, Perú: PUC Perú.

Bellatin, M. (2004). Entrevista con Mario Bellatin por Emily Hind. Confluencia 20.1, 197-204.

Bellatin, M. (2005). Obra reunida. México: Alfaguara.

Bellatin, M. (2008). Entrevista a Mario Bellatin. Asesinostimidos, agosto. Recuperado de http://asesinostimidos.blog spot.com.ar/2008/08/entrevista-mario-bellatn.html

Bellatin, M. (2008). Condición de las flores. Buenos Aires, Argentina: Entropía.

Bellatin, M. (2011). Disecado. Barcelona, España: Sexto Piso.

Bellatin, M. (2012). El libro uruguayo de los muertos. Montevideo, Uruguay: Criatura Editora.

Benjamin, W. (1936). La obra de arte en la época de su reproductibilidad técnica. En Estética y política. Buenos Aires, Argentina: Las cuarenta, 2009.

Benjamin, W. (2007). Obras, libros II/vol. I. Madrid, España: Abada Editores.

Buck-Morss, S. (2005). Walter Benjamin. Un escritor revolucionario. Buenos Aires: Eterna Cadencia.

Cherri, L. (2017a). La repetición como experiencia. Revista Brasileira de Literatura Comparada,18.28, pp. 1-16.

Cherri, L. (2017b). Imágenes de archivo en Mario Bellatin: del closet al coming out. VIII Jornadas de Filología y lingüistica. La Plata, Facultad de Humanidades y Ciencias de la Educación - UNLP, 21 al 23 de Junio.

Cherri, L. (2016). De vidrios y dobles: Mario Bellatin y la experiencia autobiográfica. IV Coloquio Internacional "Literatura y vida". Rosario, Facultad de Humanidades y Artes - UNR, 8 al 10 de junio.

Cherri, L. (2015a). Cine y literatura en América Latina: las intervenciones de Mario Bellatin. Boletim de pesquisa NELIC, Dossier "Potências do cinema", 15 (24).

Cherri, L. (2015b). Formas de la imagen en Mario Bellatin. Una pregunta por lo sensible. IX congreso Internacional Orbis Tertius «Lectores y lecturas». Homenaje a Susana Zanetti. La Plata: Facultad de Humanidades y Ciencias de la Educación - UNLP, 3 al 5 de junio.

Costello, D. (2010). Aura, rostro, fotografía: releer a Benjamin hoy. En A. Uslenghui (Comp.), Walter Benjamin: culturas de la imagen. Buenos Aires, Argentina: Eterna Cadencia.

Caygill, H. (1998). Walter Benjamin. The colour of experience. New York, EEUU: Routledge.

Crimp, D. (1980). The photographic activity of postmodernism. October 15, pp. 91-101.

Deleuze, G. (1984). La imagen-movimiento. Estudios sobre cine I. Buenos Aires, Argentina: Paidós.

Deleuze, G. (1985). La imagen-tiempo. Estudios sobre cine II. Barcelona: Paidós.

Deleuze, G. y Guattari, F. (1997). ¿Qué es la filosofia?. Buenos Aires, Argentina: Anagrama.

De Duve, Th. (2007). “Sintoma e intuição”. Novos estudos 79, pp. 210-227.

Didi-Huberman, G. (2008). Cuando las imágenes toman posición. El ojo de la historia I. Madrid, España: Machado libros.

Echevarren, R. (1998). Arte andrógino: estilo versus moda en un siglo corto. Buenos Aires, Argentina: Colihue.

Foster, H. y otros (2006). Arte desde 1900. Madrid, España: Akal.

Freud, S. (1928). Fetishism. International journal of phycho-analysis 10, pp. 161-166.

Lacan, J. (1967). Sesión 15-19/04/1967. En Le seminaire. Livre XIV: la logique du fantasme, École Lacanienne de Psychanalyse. Recuperado de http://www.ecole-lacanienne.net/

Link, D. (2015). Suturas. Buenos Aires, Argentina: Eterna Cadencia.

Link, D. (2009). Fantasmas. Imaginación y sociedad. Buenos Aires, Argentina: Eterna Cadencia.

Nancy, J.-L. (2000). Corpus. Paris, Francia: Métailié.

Oyarzun, P. (2008). Introducción. En Walter Benajamin, El narrador. Chile: Metales pesados. 
Pauls, A. (2005). El problema Bellatin. El interpretador. Literatura, arte y pensamiento, $\mathrm{n}^{\circ} 20$, abril. Recuperado de ht tp://salonkritik.net/10-11/2011/06/el_problema_bellatin_alan_paul_1.php

Ruiz, F. (2008). Vitrinas narrativas. Mario Bellatin y el relato fotográfico. Revista de Crítica Literaria Latinoamericana $68,201-210$

Walker, C. (2009). Mario Bellatin: imágenes literárias. II Congreso Internacional “Cuestiones Críticas", Rosario, Universidad Nacional de Rosario.

\section{Notas}

1 Hemos analizado el primer momento del arco de inflexiones con la fotografía de Bellatin de manera insipiente, hace algunos años (Cherri, 2015b) y con un poco más de perspectiva recientemente (Cherri, 2018). De estos trabajos se derivan las consideraciones generales que el lector hallará en la introducción y en la conclusión del presente texto. Inmediatamente, nuestra investigación nos llevó a percibir que tras su primera Obra reunida (2005) Bellatin comenzó a operar nuevos desplazamientos en su trabajo con las imágenes. Se produce, a partir del 2007, un cambio en las operaciones, especialmente las relativas a la repetición de secuencias textuales y la reescritura-juego en relación con otros autores (o con sus biografías) que se volvió inmediatamente necesario analizar (Cherri, 2016 y 2017a). Finalmente, nos resta por analizar este último momento de su producción, donde se produce un giro más metateórico pero también relacionado con el dibujo y el cine. En relación con este último sí hemos producido al respecto, especialmente en lo relacionado a el film Bola negra (2012) y la experiencia performática de Cine vivo cuya primera realización fue en 2014 (Cherri, 2015a). Finalmente, también hemos intentado pensar una reflexión sobre la imagen en la obra de Bellatin anterior al ingreso de las fotografías y su trabajo con otras artes. Es lo que denominamos "imagen de archivo" (Cherri, 2017b).

2 Si bien, en efecto, no se afirma en ningún lugar que Shiki Nagaoka sea un escritor "japonés", sería igualmente erróneo suponer que se produce una borradura de este referente. Se trata, en realidad, de una operación de sugestión que juega en el umbral mismo entre lo efectivamente dicho y lo no dicho, y la potencia imaginaria que esa tensiòn despliega, lo oriental en este caso. En los términos del propio Bellatin esta operación se denomina "falsa retórica": se trata no de "un punto de llegado sino un punto de camino, de trànsitos por no-tiempos y no-espacios" que generan vacíos o "cáscaras" referenciales, permitiendo que "el lector inmediatamente deposite una serie de elementos", es decir, dándole la posibilidad de "responder" a la escritura (Bellatin, 2004: 199). Tales elementos proliferan en el texto y se potencian con la visualidad que producen las fotos en asociación con los piés de página y, ejemplarmente, en la relación alusiva que los nombres ficticios mantienen con los reales: la "Era Meiní" alude a la "Era Meiji" de japón, Tarde de otoño de Ozu Kenzo remite a Otoño tardio de Ozu, el género "monogatarutsi" al término "monogatari”, entre otros. Para un análisis detenido de estos procesos intertextuales ver Arrieta (2015: 246-266)

3 El "plano de inmanencia" es un todo no fragmentado en el que estamos "ahora ya y siempre", no un concepto pensado ni pensable sino su límite, lo pre-conceptual: una comprensión intuitiva vinculada a la experimentación (Deleuze y Guattari 1997: 40-42). Afrontar la inmanencia implica restituir el verdadero movimiento entre lo conceptualizado y su límite caótico que tiene por plano: es alcanzar el elemento de lo paradójico en su sentido transcendente.

4 Es decir, "la experiencia de que hay algo en un objeto que trasciende nuestra experiencia de él, una opacidad interna a nuestra experiencia del objeto mismo. Lo que distingue este orden de experiencia de una experiencia más transparente, cotidiana, es que su estructura - el 'tejido peculiar de espacio y tiempo'- hace palpable esta opacidad y por lo tanto ofrece un momento de trascendencia dentro del horizonte inmanente de nuestra experiencia misma" (Costello 2010: 115)

5 Explica Caygill: "the active nihilist response of revolutionising all structures and redirecting the energies released by war into constructive channels" (1998: 117).

6 Explica Oyarzún: "Benjamin no limita su observación a la comunicabilidad de la experiencia, como si se tratara de un proceso extrínseco a ésta; por el contrario, entiendo que presupone que es esencial a la experiencia dicha comunicabilidad, y que un quiebre de la última equivale a un quiebra de la primera [...] lo que Benjamin llama 'comunicabilidad (mitteilbarkeit) de la experiencia' no se refiere a modos o procesos de equivalencia u homologación universal de las experiencias (en concordancia con 'universos' culturales determinados), sino a formas de participación en una experiencia común, la cual, sin embargo, no está pre-constituida, sino que deviene común en la comunicación y en virtud de ella (2008: 13). 